\title{
Limites e possibilidades da formação inicial para o desenvolvimento de práticas docentes autônomas
}

\section{The initial formation limits and possibilities to the development of teaching autonomous practices}

\author{
Mônica Vasconcellos ${ }^{1}$ \\ Mariana Lima Vilela ${ }^{1}$
}

\begin{abstract}
RESUMO
Este artigo reúne bases empíricas de dois projetos de pesquisa mais amplos que focalizam as relações entre formação e profissão docente em cursos de Pedagogia e de Licenciatura em Ciências Biológicas. Objetivamos investigar os saberes mobilizados e/ou produzidos por professores especialistas e polivalentes para o desenvolvimento de práticas autônomas e sua relação com a formação inicial. Mobilizamos referenciais teóricos dos Saberes Docentes para a análise da autonomia docente sob um enfoque relacional em depoimentos de professores da educação básica. As informações sobre experiências formativas na graduação e na fase inicial da carreira do magistério foram adquiridas por meio de entrevistas e discussão coletiva e as análises buscaram problematizar relações entre formação, profissão e condicionantes que favorecem o desenvolvimento de práticas autônomas. Os resultados evidenciam fragilidades relativas à formação no que tange às práticas docentes, com destaque para: domínio de conteúdos e metodologias de ensino. Os depoimentos apontam, também, que determinados temas foram mal compreendidos ou despertaram pouco interesse na ocasião da graduação, mas passaram a fazer sentido ou a gerar inquietações após os embates com as exigências da escola. As interpretações dos depoimentos apontam para a necessidade de valorização da dimensão profissional da
\end{abstract}

DOI: $10.1590 / 0104-4060.46646$

1 Universidade Federal Fluminense. Faculdade de Educação. Niterói, Rio de Janeiro, Brasil. Rua Professor Waldemar Freitas Reis, s/nº. Campus do Gragoatá - Bloco D - $4^{\circ}$ andar - sala 412. CEP: 24.210-201.E-mails: monicavasconcellos@id.uff.bre m.limavilela@gmail.com 
docência durante a formação inicial, como condição para o desenvolvimento de práticas autônomas.

Palavras-chave: formação docente; formação inicial; profissão docente; autonomia.

\begin{abstract}
This article gathers empirical bases from two wider research projects which focus the relations between docent training and profession at the Education and the Biological Sciences Teaching courses. Our goal was to investigate the acquired and produced knowledge by experts and multifunctional teachers for the development of autonomous practices, and its relation with the initial formation. We mobilized the theoretical references about Docent Knowledge to analyse the autonomous teacher under a relational emphasis on the testimonies of elementary education teachers. Information about formative experiences during graduation and the teaching career initial phase was acquired by interviews and collective discussions, and the analyses sought to question the relations between formation, profession and circumstances that contribute to the autonomous practices development. The results emphasize fragilities related to the formation when it comes to teacher training, highlighting the mastery of content and teaching methodology. The testimonies show, also, that some topics were misunderstood or were not able to induce much interest at graduation, but they started to make sense or to help by generating concerns after clashes with the school demands. The testimonies' interpretation points to the need of valuing the docents' professional dimension during their initial formation, as a condition to autonomous practices development.
\end{abstract}

Keywords: teacher training; initial formation; docent profession; docent autonomy.

\title{
A autonomia docente compreendida sob um enfoque relacional
}

O debate internacional sobre autonomia docente é marcado por enfoques distintos e, portanto, está longe de ser consensual. Se, para alguns, essa variação de entendimentos pode suscitar distorções conceituais, em nossa compreensão é rica e propícia a análise da complexidade do trabalho do professor, tendo em vista que abarca elementos variados que atuam e interferem em seu cotidiano profissional.

Adotamos uma noção relacional da autonomia, distanciando-nos da ideia de que ela equivale a um extremo oposto do controle exercido sobre o trabalho 
docente. Rejeitamos, portanto, a ideia de "busca" ou de "resgate" de uma autonomia supostamente inacessível, pois constrangida por mecanismos de controle e cerceamento da liberdade. Também questionamos seu esvaziamento pela progressiva proletarização do magistério em oposição direta ao papel do professor como profissional autônomo, apontadas por Moreira (2012) e Contreras (2002).

Aproximamo-nos de uma noção de autonomia que não seja a oposição extrema ao controle, mas que se constrói e que se negocia permanentemente. Assim, compreendemos que a autonomia não é conquistada - como algo essencial a ser alcançado -, ela é construída no diálogo com regulações múltiplas (LESSARD, 2006) e, portanto, não existe sem essas regulações.

A partir dessas reflexões, colocamo-nos ao lado de Selles e Andrade (no prelo, p. 8) ao compreender a autonomia docente como "[...] um jogo jogado entre regulação, resistência e modulação". Os referidos autores defendem que a autonomia é exercida nas tensões entre as "estratégias de regulação e as táticas de modulação". (SELLES; ANDRADE, no prelo, p. 5). Segundo eles, constituem-se em estratégias de regulação:

(i) o Estado, a burocracia estatal e as políticas públicas educacionais; (ii) o mercado, a lógica mercantil e privatista em educação e a indústria cultural, especialmente o setor de produção didático-pedagógica; (iii) a pesquisa acadêmica compreendida em uma perspectiva prescritiva, que toma a educação, a escola e a profissão docente não pelo que efetivamente são, mas pelo que lhes falta ou pelo que deveriam ser; (iv) o movimento social dos professores e as iniciativas de organização e de mobilização sindical, numa perspectiva ético-profissional; (v) o currículo e a própria estrutura disciplinar do trabalho docente, envolvendo demandas internas de gestão e externas, do âmbito do que tem sido chamado de noosfera. (SELLES; ANDRADE, no prelo, p. 5).

E como táticas de modulação da autonomia docente os referidos autores apontam: as histórias de vida dos professores, os laços profissionais locais, cotidianamente construídos nos ambientes e coletivos profissionais; os acordos locais de gestão escolar.

As táticas de modulação, portanto, parecem ser fundamentais para o desenvolvimento de práticas autônomas, pois configuram-se como lócus de possibilidade de ação, de tomada de decisões e assunção de responsabilidades. Nesse sentido, mobilizamos visões complementares delineadas por Petroni e Souza (2010) e por Nóvoa (2011) buscando aprofundar a compreensão sobre as táticas de modulação da autonomia docente em diferentes esferas de regulação. 
Ao discutir a temática da autonomia docente, Petroni e Souza (2010) evidenciam o modo ambíguo com o qual os docentes têm sido socialmente retratados, seja porque são oprimidos pelo sistema de ensino e/ou pela gestão da escola; porque são incitados a romper com os ditames "das autoridades" e, ao mesmo tempo, apontados pelas mídias, alunos e seus familiares, como culpados pelo fracasso desse mesmo sistema.

Para analisar o conflituoso quadro que evolve a autonomia docente, as pesquisadoras recorrem aos conceitos de liberdade e emancipação de Paulo Freire e ao conceito de autorregulação de Vygostsky. Com base nas articulações que estabelecem, afirmam que a autonomia docente se constitui no exercício desses três elementos e a definem

[...] como sendo a capacidade que o sujeito adquire para formular as próprias leis e regras durante o seu processo de desenvolvimento e por meio das relações estabelecidas com os outros, no contexto em que está inserido. (PETRONI; SOUZA, 2010, p. 358).

Por outro lado, considerando as influências das políticas educacionais, do currículo e as difíceis condições de trabalho enfrentadas cotidianamente pelos docentes, Nóvoa (2011) ressalta que é considerável o volume de pesquisas relacionadas aos docentes, cujos resultados têm contribuído com o desenvolvimento do campo. Entretanto, adverte que embora sejam o foco do debate "[...] os professores não foram os autores desses discursos e, num certo sentido, viram o seu território profissional e simbólico ocupado por outros grupos". (NÓVOA, 2011, p. 534-535). Sugere a adoção de práticas colaborativas que valorizem a partilha de saberes e o respeito à autonomia, via reformulação das políticas públicas e alteração das condições de trabalho. Enfatiza, ainda, a implementação de situações que envolvam estudo e reflexão coletiva, em detrimento da ênfase no controle dos processos de ensino.

Advertidos pelas ideias de Petroni e Souza (2010) e Nóvoa (2011), focalizamos especialmente as táticas de modulação construídas por professores, frente às forças de regulação, como esferas fundamentais para o desenvolvimento de práticas autônomas. (SELLES; ANDRADE, no prelo). Defendemos que é na aprendizagem dessas "táticas" que os professores desenvolvem o que estamos compreendendo como autonomia docente. 


\title{
A perspectiva dos saberes docentes como referencial para a constituição da autonomia docente
}

Os estudos relacionados aos saberes dos professores foram iniciados no Brasil, a partir do artigo de Tardif, Lessard e Lahaye (1991) que passou a constituir-se como importante referência ao tema nas pesquisas educacionais. Valorizando o caráter produtor de conhecimentos, os autores consideram que o saber docente é composto a partir de diferentes fontes. Portanto, o ofício docente constitui-se como uma prática intelectual e social em que se articulam os diferentes saberes, sendo essa a condição para a consolidação dos professores como grupos profissionais.

No que se refere às relações entre a formação e a profissão, os pesquisadores advertem que:

\begin{abstract}
Engendram-se assim, relações problemáticas dos docentes com seus saberes, as quais sempre implicam, no fundo, uma certa distância - social, institucional e epistemológica - que os separa e os desapropria desses saberes produzidos, contratados e legitimados por outros. (TARDIF; LESSARD; LAHAYE, 1991, p. 223).
\end{abstract}

Assim, por não validarem os saberes de sua formação, os professores tendem a ancorar-se na produção de saberes próprios da sua prática profissional, os quais compreendem, reconhecem e dominam.

A valorização dos saberes da experiência expõe, assim, os limites da formação inicial, no que se refere ao enfrentamento dos fatores imponderáveis da profissão como: as relações e interações que os professores desenvolvem com os demais atores no campo da sua prática; as normas e obrigações a que o trabalho cotidiano é submetido, e aspectos diversos da organização escolar.

Para Tardif, Lessard e Lahaye (1991) a prática profissional não é um processo de aplicação de conhecimentos universitários, mas de "filtração" que os dilui e os transforma em função das exigências do trabalho. Portanto, podemos salientar que na tensão entre regulação e modulação são construídos e validados os saberes da experiência, sendo nesse tempo/espaço também construídas práticas autônomas. Essa ideia se aproxima do que propõe Gauthier (1998), a considerar que a compreensão dos elementos que compõem o 
[...] saber profissional docente é fundamental e pode permitir que os professores [e futuros professores] exerçam o seu ofício com muito mais [conhecimento e segurança, por meio do entendimento de questões como:] O que acontece quando o professor ensina? O que ele faz exatamente para instruir e educar as crianças? [...] Quais são os saberes [...] mobilizados na ação pedagógica? (GAUTHIER et al., 1998, p. 17-18).

Nesse sentido, os cursos de formação inicial têm importante papel, tendo em vista que ao ingressar nas licenciaturas, os alunos levam consigo ideias e conhecimentos estabelecidos que precisam ser confrontados aos estudos desenvolvidos durante esse processo. (GARCIA, 2002).

Segundo Tardif (2000), o dia a dia, os conhecimentos abordados nas universidades "[...] estão longe de abranger todos os saberes dos professores no trabalho" (TARDIF, 2000, p. 12), revelando um descompasso entre aquilo que é abordado na graduação e os problemas enfrentados nas escolas. Por sua vez, ao começar a lecionar, os docentes se deparam com um ambiente complexo para o qual sentem-se despreparados e neste processo que produzem, mobilizam e ressignificam seus saberes, embora nem sempre tenham consciência disso. (LIMA, 2006).

No presente trabalho, pautamos nossas análises na noção de que o saber docente refere-se:

[...] unicamente [aos] pensamentos, às idéias, [aos] juízos, [aos] discursos, [aos] argumentos que [obedecem] a certas exigências de racionalidade. [Isto é, eu] falo ou ajo racionalmente quando sou capaz de justificar, por meio de razões, de declarações, de procedimentos, etc. Essa 'capacidade' ou essa 'competência' é verificada na argumentação, isto é, num discurso em que proponho razões para justificar meus atos. Essas razões [por sua vez], são discutíveis, criticáveis e revisáveis. (TARDIF, 2005, p. 199).

No conjunto das reflexões até aqui apresentadas, as relações entre os saberes docentes e autonomia sob um enfoque relacional reforçam nossas inquietações e nossa intenção de compreender quais são as possibilidades de contribuição da formação inicial para o desenvolvimento de práticas autônomas.

Tais inquietações mobilizam questões, pelo menos quanto a dois aspectos: de um lado, as críticas que os cursos de licenciatura têm recebido acerca das suas próprias limitações que geram comprometimentos na atuação dos novos docentes, decorrentes, entre outros fatores, do desalinho entre os saberes cons- 
tituídos/mobilizados pelos professores no exercício do seu trabalho e os estudos realizados no interior dos cursos de graduação. (GATTI, 2009; TARDIF, 2005). De outro, os estudos da área indicam que os docentes se defrontam com as demandas do ambiente escolar e acabam reproduzindo práticas vividas durante sua história de vida, em razão desse mesmo distanciamento.

\section{Objetivos e metodologia da pesquisa}

Adotamos uma compreensão relacional da autonomia docente aqui delineada para investigar os saberes mobilizados e/ou produzidos por professores especialistas e polivalentes, para o desenvolvimento de práticas autônomas e sua relação com a formação inicial. Em síntese, perseguimos as seguintes questões: Que circunstâncias contribuem para que professores desenvolvam práticas autônomas, ou aprendam táticas de modulação? De que formas a formação inicial de professores pode contribuir para essa aprendizagem?

Tomamos como fontes empíricas depoimentos de quatro professores da educação básica, sendo dois deles graduados em Ciências Biológicas e responsáveis por turmas dos anos finais do ensino fundamental e/ou do Ensino Médio e os demais formados em Pedagogia e responsáveis por turmas dos anos iniciais do ensino fundamental. As informações fornecidas pelos dois primeiros foram obtidas por meio de entrevistas realizadas individualmente e os outros dois participaram de uma discussão coletiva. Em ambos os casos, contamos com o apoio de roteiros semiestruturados, previamente elaborados, buscando que os professores falassem sobre sua formação inicial e sobre os primeiros anos da profissão, focalizando aspectos dos saberes docentes e autonomia. Os depoimentos foram gravados e transcritos. O conjunto dos dados foi comparado e organizado em seis categorias, assim denominadas: a) Contribuições da licenciatura para a realização de atividades profissionais, especialmente no que diz respeito ao planejamento das aulas ou à avaliação dos alunos; b) Desconhecimento de determinados conteúdos e/ou de procedimentos metodológicos necessários ao ensino; c) Forte ênfase na formação específica desarticulada da escola; d) O tempo de experiência como gerador de aprendizagens; e) Controle ou omissão excessiva, por parte da gestão da escola, influenciando o trabalho em sala de aula; f) Compromisso profissional como requisito para o exercício da autonomia. No âmbito deste artigo, centramos nossas análises apenas nas duas primeiras categorias, em diálogo com o referencial teórico selecionado. 


\section{Resultados}

Contribuições da licenciatura para a realização de atividades profissionais, especialmente no que diz respeito ao planejamento das aulas ou à avaliação dos alunos

As informações compartilhadas pelas professoras, a respeito dos seus respectivos cursos de licenciatura, de um lado nos fornecem pistas acerca das insuficiências desses cursos e, de outro, evidenciam elementos considerados relevantes para a realização do seu trabalho. Foram esses elementos que nos chamaram atenção, tendo em vista que dentre os quatro professores envolvidos, três destacaram aprendizagens relacionadas ao planejamento das aulas ou à avaliação dos alunos como principais contribuições da licenciatura. Para ilustrar, referiram-se especificamente a uma determinada disciplina cursada ou a alguma referência bibliográfica estudada na época. Ressaltaram, inclusive, que os estudos realizados não foram devidamente compreendidos na ocasião e que só fizeram sentido quando se defrontaram com situações reais vividas no exercício da profissão:

[...] eu não era uma pessoa que planejava os meus seminários... Eu não planejava minhas aulas, assim. Eu não fazia o planejamento que tinha que ser feito. Eu planejava de uma forma que não era suficientemente boa. [...] Muita coisa do que eu sou agora, é claro que é com a experiência, mas muita coisa a [componente curricular] Prática de Ensino me ajudou, sem sombra de dúvida. (PROFESSORA PAULA).

Aquela [avaliação] processual lá, que a gente escuta tudo e na hora [da aula na universidade] a gente não sabe como é que faz aquilo. É quase um puxão de orelha, porque agora [que estou na escola] eu lembro da faculdade. (PROFESSORA GIOVANA).

Sabe o que é que eu lembro? Um dia desses eu não sabia corrigir. Sabe como é que eu estava fazendo pra corrigir? Estava escrito dez, com "s". Eu li na Nova Escola, um professor falando, que a gente não deve colocar, por exemplo, lá o dez com "z" [na atividade do aluno]. Eu pegar e colocar em cima do "s" o " $z$ ". Porque o meu aluno nunca vai saber onde ele errou. A Telma Vaz sempre falou isso. Ai eu lembrei que 
eu tinha lido a Telma Vaz [na faculdade] e ela tinha um capitulo lá que falava sobre correção, que a gente não pode dar a resposta, entendeu? (PROFESSORA AMANDA).

Embora tenham percorrido caminhos bastante distintos durante suas trajetórias de vida pessoal e profissional, os esclarecimentos das três professoras evidenciam semelhanças acerca das contribuições da formação inicial, em relação às questões do campo profissional docente. Os depoimentos apontam, também, que determinados temas foram mal compreendidos ou despertaram pouco interesse na ocasião da graduação, mas passaram a fazer algum sentido ou a gerar inquietações após os embates com as exigências da escola.

No caso da professora Paula, verificamos a presença de uma referência importante acerca do componente curricular "Prática de Ensino" que, para ela, foi responsável por contribuir de forma mais efetiva com o desenvolvimento do trabalho, na escola. As outras duas recordaram-se de estudos pontuais sobre questões que envolviam a avaliação dos alunos. Curiosamente, todas referiram-se às exigências do cotidiano da profissão como desencadeadoras da necessidade de buscar informações ou rememorar o que foi estudado durante a licenciatura.

Estudos relacionados a essa temática (DINIZ-PEREIRA, 2011; GATTI, 2012; GAUTHIER et al., 1998) coadunam com essas informações e revelam que, na maior parte das vezes, os cursos de licenciatura são fortemente criticados por egressos e pesquisadores, em razão de motivos que referem-se, principalmente, ao distanciamento entre a formação inicial e o exercício da profissão docente.

Gauthier et al. (1998, p. 35) explica que apesar da forte contribuição científica que os pesquisadores ligados às faculdades de educação nos oferecem por meio da produção de conhecimentos que evidenciam a relevância dos saberes docentes, há um considerável distanciamento entre os resultados dessas pesquisas e o encaminhamento do trabalho, nas licenciaturas, que compromete a formação dos futuros professores. Para o pesquisador, esse problema precisa ser enfrentado e superado,

[...] pondo-se em evidência um saber da ação pedagógica legitimado pela pesquisa e pela própria atividade dos professores e integrado na formação docente. Desse modo, a formação inicial, recebida na Universidade, refletiria melhor a prática no meio escolar, e o saber do próprio professor, difundido no seio da Universidade, acharia aí um reconhecimento de sua pertinência. (GAUTHIER et al., 1998, p. 35). 
Abarca (1999) acrescenta que a pouca atenção dedicada pelas instituições formadoras às demandas do ofício de professor, aliada ao pouco apoio e à precária situação que os docentes enfrentam no ambiente de trabalho interferem em sua atuação e comprometem a atividade docente, bem como afetam seu desenvolvimento profissional.

Para lidar com problemas desse tipo, as professoras Amanda e Giovana acreditavam que seria importante que as licenciaturas inserissem os alunos no meio escolar e que os estudos realizados levassem em conta a formação para o ensino e para o enfrentamento das dificuldades com as quais os docentes se defrontam na profissão. Isso é, na formação inicial, os futuros professores precisariam ter a chance de se aproximarem dos saberes que emergem da experiência dos seus pares, por meio de estudos/discussões/atividades/pesquisas dessa natureza.

Por tudo o que foi discutido até aqui, finalizamos este tópico lembrando que o tempo de experiência no magistério foi mencionado direta ou indiretamente pelas professoras como elemento que possibilita a constituição de soluções para os problemas enfrentados. Embora estejamos afinadas com a compreensão de sua relevância na constituição dos saberes docentes (TARDIF, 2005) rechaçamos a ideia de atribuir-lhe a responsabilidade pela superação das insuficiências acarretadas pela graduação, tendo em vista a responsabilidade que os cursos de licenciatura têm no processo de formação para o magistério. Em outras palavras, deixar a cargo da experiência a constituição de saberes ligados à profissão pode significar a manutenção do distanciamento entre questões profissionais e formação docente, designando ao egresso a responsabilidade pela superação dessas lacunas quando estiver inserido no ambiente escolar.

\section{Desconhecimento de determinados conteúdos elou de procedimentos metodológicos necessários ao ensino}

Se a categoria anterior aborda aspectos da formação inicial mencionados pelas professoras como relevantes para o exercício profissional e deixa nas entrelinhas o entendimento de que, embora importantes, as contribuições foram esparsas, essa categoria, por sua vez, denota com maior objetividade suas insuficiências.

E aí você recebe lá o conteúdo do primeiro ano [do ensino médio]. Você olha pra aquilo: Caramba! Como é que eu vou trabalhar isso? Quando a gente se reúne lá, as reuniões de colegiado, a gente discute os pontos nodais dos conteúdos, mas assim, metodologicamente falta um pouco 
daquilo que tem nos colégios, que tem uma equipe que tem tempo pra se reunir e tal. (PROFESSOR ANTÔNIO).

Os professores dessa parte, da Biologia, eu não sei se deveria ser diferente, assim, mas eles são acadêmicos e dão o curso como um bacharelado normal. Essas ênfases não são dadas então no curso. Então você acaba seguindo pelo que você aprendeu mais ou menos [...]. Então assim, eu tentei. E eu acho que me acrescentou e me ajudou mais nisso, nessa seleção. Então acaba que o que eu faço, assim é pelo que eu tive mais enfoque, ou o que eu acho que vai ajudar mais. (PROFESSORA PAULA).

[...] o grande problema que eu estava comentando com $M$, é que eu não sei conteúdo (risos). Eu sei o conteúdo, se você me der uma conta pra resolver, eu sei. Eu só não sei como é que eu vou ensinar aquilo [...]. Então, o que é que eu fiz esta semana? Eu peguei e dei para as crianças, sem explicar, sem nada, pra ver o que é que vai sair. Tanto é que eles conseguiram. Eles entenderam e eu não. (PROFESSORA AMANDA).

Eu tenho dificuldade em História e Geografia. História e Geografia mais pelo fato de não ter conteúdo [claramente definido pela escola]. O livro trouxe História e Geografia junto, e aí agora acabou! Não tem mais conteúdo. Ai eu tive que fuçar um livro só de História e um livro só de Geografia, pra separar. (PROFESSORA GIOVANA).

Os excertos registrados anteriormente têm em comum preocupações que envolvem o domínio de conteúdos e de metodologias de ensino, elementos essenciais à prática docente. Os professores Antônio e Paula, por exemplo, apontam limitações metodológicas como empecilhos que precisam enfrentar no cotidiano profissional. Em decorrência disso, Paula faz críticas à formação inicial, por julgar que essa restrição se deve, principalmente, ao fato de que sua licenciatura esteve mais próxima de um bacharelado. Em contrapartida, acredita que esse enfoque contribuiu para sua compreensão em relação ao domínio de conteúdos vinculados ao campo da Biologia, o que a auxilia no desenvolvimento do trabalho. Para resolverem esse problema esperam ajuda da escola, agem por tentativa e erro e/ou recorrem às estratégias adotadas por seus professores no período escolar.

As professoras Amanda e Giovana revelaram dificuldades que abrangem tanto conteúdos que precisam ensinar, como possibilidades metodológicas que 
poderiam adotar. Para lidar com essa situação, algumas vezes recorrem aos próprios alunos (AMANDA) ou buscam fontes que consideram confiáveis (GIOVANA).

O conjunto das informações adquiridas nos leva a questionar: " $[$...] ' $\mathrm{O}$ que [de fato], os professores [...] precisam saber'? ou 'Quanto um professor deve saber antes de ir para a sala de aula?' [...]”. (SHULMAN; GROSSMAN; WILSON, 1989, p. 27).

A literatura indica que os cursos que formam professores para os anos iniciais, no geral, enfatizam conhecimentos pedagógicos e curriculares em detrimento dos conhecimentos de conteúdo (CURI, 2004; SHULMAN, 1987), entre outros motivos, em razão da crença de que a aprendizagem de metodologias diversificadas sustentará o trabalho docente, nesse segmento escolar. O inverso ocorre quando se trata da formação dos professores que atuarão nos anos finais do ensino fundamental e médio, por considerarem que ao dominar conteúdos terão condições de ensiná-los sem maiores dificuldades. Na realidade, tanto uma como outra abordagem prejudicam a formação dos futuros profissionais, aumentando o número de problemas relacionados ao trabalho docente. (FREITAS, 2001; GOMES, 2002).

Seja em um caso ou outro, pesquisadores da área (CURI, 2004; NACARATO, 2000) indicam que, na maior parte das vezes, os estudos desenvolvidos nos cursos de formação têm ocorrido de forma descontextualizada, sem levar em conta as reais necessidades suscitadas pela docência.

\section{Considerações finais}

Relações entre a formação de professores e a profissionalização do ensino: uma via a ser considerada na constituição da autonomia docente

As relações entre a formação e a profissão docente são uma arena de disputas de sentidos, os quais merecem ser explicitados para a defesa daquilo que compreendemos como possibilidades de desenvolvimento de práticas autônomas na perspectiva aqui adotada.

Por um lado, quando assumimos que a formação inicial é incompleta e que, portanto, se fazem necessárias ações de formação continuada para complementá-la, corremos o risco de fragilizar o caráter profissional da docência, apontando que essa profissão tem fragilidades e precisa ser "aperfeiçoada". Por outro lado, se valorizarmos a dimensão profissional no interior da própria formação incor- 
remos na armadilha de reduzir a formação à profissão, fragilizando uma luta histórica pela valorização das Ciências da Educação na formação de educadores como "mais do que professores", com uma formação acadêmica sólida como defendida pela comunidade de Pedagogos. (FREITAS, 2002, 2007).

Talvez seja por esse "cobertor curto" que as relações entre a formação e a profissão sejam tão debatidas teoricamente, mas com poucas soluções curriculares e metodológicas que cheguem a uma dupla valorização da profissão e, ao mesmo tempo, de uma formação que não reduza a docência a uma profissão sob aspecto pragmático de mero atendimento às demandas sociais. Essa tensão se materializa historicamente em diversos países, no próprio movimento de progressiva extinção dos cursos normais de nível médio e defesa da formação docente exclusiva em nível superior. Segundo Tardif (2013), o que se perdeu nessa transição foi exatamente a dimensão profissional da docência. Então, qual é o lugar da profissão docente na formação de professores? Quais as relações entre profissão, formação e o desenvolvimento de táticas de modulação para a construção da autonomia docente? E a formação contínua, de que maneira pode contribuir com a profissão?

Compreender as tensões entre formação e profissão ganha centralidade para pensarmos sobre a autonomia docente na perspectiva aqui adotada, pois se assumimos que a autonomia se desenvolve a partir da experimentação de táticas de modulação frente às estratégias de regulação, então o locus dessa experimentação durante a formação se configura na sua dimensão profissional. Apenas na relação com o trabalho e a profissionalidade docente é que se faz possível ter contato com as estratégias de regulação e, portanto, para a construção e consolidação de saberes profissionais e o desenvolvimento de práticas autônomas. Em outras palavras, é na vivência da profissão que se experimentam táticas de modulação, pois é também nessa vivência que a docência está sujeita às estratégias de regulação.

Ao assumirmos que a autonomia é construída na relação que os professores constroem com os sujeitos com os quais se relacionam - alunos, colegas, gestores - situados e condicionados às circunstâncias políticas e institucionais sobre as quais trabalham, então é certo que a dimensão profissional da docência não será a única, mas será um locus insubstituível para a experimentação, a tentativa e erro, a assunção de responsabilidades e riscos, assim como a de escolhas e caminhos possíveis na realização do trabalho docente.

Nesse sentido, entendemos que sem a dimensão profissional da docência durante a formação inicial, as condições para o desenvolvimento de práticas autônomas se esvaziam, se idealizam, se artificializam ou até mesmo são subtraídas. Assim, os campos empíricos mais férteis de investigação do desenvolvimento de práticas autônomas, da forma como aqui compreendemos, são os 
de interseção entre as dimensões formativas e profissionais da docência: seja nos espaços curriculares e no encaminhamento efetivo da formação inicial em que os elementos profissionais se apresentam, seja nas diferentes experiências formativas que professores em exercício profissional vivenciam no trabalho cotidiano.

Defendemos, enfim, uma valorização dos espaços de interseção entre a formação e a profissão, tanto dos elementos profissionais presentes na formação inicial, quanto dos elementos formativos que podem estar presentes nos primeiros anos do exercício do magistério. Entendemos que essa valorização depende de uma revisão das relações entre universidade e escola nos processos de formação docente e desenvolvimento profissional.

\section{REFERÊNCIAS}

ABARCA, J. C. Professores que se inician en la docência: algunas reflexiones al respecto desde America Latina. Revista Iberoamericana de Eduación, Organización de Estados Iberoamericanos para la Educación, la Ciencia y la Cultura, n. 19, p. 51-100, 1999.

CONTRERAS, J. A autonomia de professores. 2. ed. São Paulo: Cortez, 2002.

CURI, E. Formação de professores polivalentes: uma análise de conhecimentos para ensinar Matemática e de crenças e atitudes que interferem na constituição desses conhecimentos. Tese (Doutorado em Educação Matemática), PUC-SP, São Paulo, 2004.

DINIZ-PEREIRA, J. E. O ovo ou a galinha: a crise da profissão docente e a aparente falta de perspectiva para a educação brasileira. Revista Brasileira de Estudos Pedagógicos, v. 92, n. 230 , p. $34-51,2011$.

FREITAS, H. C. L. Formação de Professores no Brasil: 10 anos de embates entre projetos de formação. Educação e Sociedade, v. 23, n. 80, p. 137-168, 2002.

FREITAS, H. C. L. A (nova) política de formação de professores: a prioridade postergada. Educação e Sociedade, v. 28, p. 1203-1230, 2007.

FREITAS, J. L. M. Uma reflexão sobre crenças relativas à aprendizagem matemática. Série-Estudos, n. 11, p. 99-109, 2001.

GATTI, B. A. Políticas e práticas de formação de professores: perspectivas no Brasil. XVI ENDIPE- Encontro Nacional de Didática e Práticas de Ensino, Campinas, 2012.

GATTI, B. A. Atratividade da carreira docente. Relatório de Pesquisa. São Paulo: Fundação Carlos Chagas; Fundação Victor Civita, 2009. 
GAUTHIER, C. et al. Por uma teoria da pedagogia: pesquisas contemporâneas sobre o saber docente. Ijuí: Ed. UNIJUÍ, 1998.

GOMES, M. G. Obstáculos epistemológicos, obstáculos didáticos e o conhecimento matemático nos cursos de formação de professores das séries iniciais do ensino fundamental. Contrapontos, n. 6, p. 363-388, 2002.

LESSARD, C. Regulação múltipla e autonomia profissional dos professores: comparação entre o Quebec e o Canadá. Educação em Revista, v. 44, p. 143-163, 2006.

LIMA, E. F. de. Sobre(as)vivências no início da docência: que recados elas nos deixam?... In: LIMA, E. F. (Org.). Sobrevivências no início da docência. Brasília: Líber Livro Editora, 2006. p. 91-100.

MARCELO GARCIA C. La formación inicial y permanente de los educadores. In: MARCELO GARCIA C. Consejo Escolar del Estado: Los educadores en la sociedad del siglo XXI. Madrid: 2002. p. 161-194.

MOREIRA, A. F. B. Em busca da autonomia docente nas práticas curriculares. Revista Teias. v. 13. n. 27, p. 27-47, 2012.

NACARATO, A. M. Educação continuada sob a perspectiva da pesquisa-ação: Currículo em ação de um grupo de professoras ao aprender ensinando Geometria. Tese (Doutorado em Educação), UNICAMP, Campinas, 2000.

NÓVOA, A. et al. Pesquisa em educação como processo dinâmico, aberto e imaginativo: uma entrevista com António Nóvoa. Educação e realidade, v. 36, n. 2, p. 533-543, 2011.

PETRONI, A. P.; SOUZA, V. L. T. de. As relações na escola e a construção da autonomia: um estudo da perspectiva da Psicologia. Psicologia e Sociedade, v. 2, n. 22, p. 364, 2010.

SELLES, S. E.; ANDRADE, E. P. de. Políticas curriculares e subalternização do trabalho docente. No prelo.

SHULMAN, L.; GROSSMAN, P. L.; WILSON, S. M. Teachers of substance: subject matter knowledge for teaching. In: REYNOLDS, M. C. (Org.). Knowledge base for the beginning teacher. New York: Pergamon Press, 1989. p. 23- 36.

SHULMAN, L. Knowledge and teaching: foundations of the new reform. Harvard Educational Review, n. 1, p. 1-22, February 1987.

TARDIF, M. A profissionalização do ensino passados trinta anos: dois passos para a frente, três para trás. Educação e Sociedade. Campinas, v. 34, n. 123, p. 551-571, 2013.

TARDIF, M. Saberes docentes e formação profissional. 5. ed. Petrópolis: Vozes, 2005.

TARDIF, M. Saberes profissionais dos professores e conhecimentos universitários: elementos para uma epistemologia da prática profissional dos professores e suas consequências em relação à formação para o magistério. Revista Brasileira de Educação, n. 13 , p. $5-24,2000$. 
TARDIF, M.; LESSARD, C. O trabalho docente: Elementos para uma teoria da docência como profissão de interações humanas. Petrópolis: Vozes, 2005.

TARDIF, M.; LESSARD, C.; LAHAYE, L. Os professores face ao saber docente: esboço de uma problemática do saber docente. Teoria e Educação, n. 5, p. 215-233, 1991.

Texto recebido em 03 de junho de 2016. Texto aprovado em 03 de novembro de 2016. 